\title{
Self-sensing Piezoresistive Composites Based on Cement Incorporating Low Dosage of Carbon Black Used as Multifunctional Construction Materials
}

\author{
MARIUS-GEORGE PARVAN ${ }^{1}$, GEORGETA VOICU ${ }^{1 *}$, ALINA-IOANA BADANOIU ${ }^{1}$, \\ VICTOR OPRISAN FRUTH ${ }^{2}$ \\ ${ }^{1}$ University Politehnica of Bucharest, Faculty of Applied Chemistry and Material Science, Department of Science and \\ Engineering of Oxide Materials and Nanomaterials, 1-7 Gh. Polizu Str., 011061, Bucharest, Romania \\ ${ }^{2}$ Institute for Physical Chemistry of the Romanian Academy of Sciences "Ilie Murgulescu", 202 Splaiul Independentei 202, \\ 060021, Bucharest, Romania
}

\section{HIGHLIGHTS}

-Carbon black (CB) particles in nanometric domain can be successfully incorporated in cement matrices in order to obtain special concretes/mortars with self-sensing properties.

-Piezorezistivity monitoring of mortars is a non-destructive method used to assess the structural characteristics of composite materials.

-The presence of $C B$ in studied mortars provides a specific electrical sensitivity which may change when curing time increases.

Abstract. The paper presents the manufacture and characterization of special mortars based on Portland cement $(P C)$ and a nanopowder with electrical properties (carbon black - CB). These materials were characterized from the point of view of mechanical strengths as well as properties specific for self-sensing materials i.e. variation of electrical signal when applying a mechanical strain. The electrical signal and mechanical strength values are strongly dependent on the composition and microstructure of mortars.The values of electrical resistance are strongly correlated with the composition, morphology and curing time of the mortars. In this study significant changes of the electrical behaviour (piezoresistivity) of the mortars vs. curing time (90 or 180 days) were noticed, so this must be considered in practical applications. The best results were obtained for the mortars with 0.5-3 wt.\% CB cured for 180 days.

Keywords: Portland cement; Carbon black; Functional fillers; Piezoresistivity

\section{Introduction}

The degradation of civil infrastructures due to load, fatigue, erosion or aging, is the main reason for the failure of concrete structures [1]. Therefore, the monitoring of civil infrastructures is of high importance and a new discipline emerged i.e. structural health monitoring (SHM). SHM of concretes/mortars is carried out in order to provide information regarding the structural quantification in terms of durability and can contribute to extend their service life [2-8]. The recent partial collapse of a highway bridge in Genoa Italy, in July 2018 is a recent example stressing the importance of this domain.

Most sensors presently used for SHM of concrete structures are made of metals; they are attached to or embedded in concrete, therefore can easily be separated or/and corroded during service. Also, metal sensors have a low sensitivity and low survival rate $[9,10]$. These are some of the reasons which determined the development of self-sensing concretes.

The electrical resistivity of a cementitious composite (e.g. mortar) can be reduced by addition of conductive fillers, thus promoting an insulator-to-conductor transition. Piezoresistivity is a physical property of materials and is defined as the change of electrical resistivity when a material is subjected

*email: georgeta.voicu@upb.ro 
to mechanical strain $[6,11]$. If the electric resistivity increases with the increase compressive strain, piezoresistivity is defined to be positive; otherwise, piezoresistivity is negative.

Cement-based sensors contain the following phases: (a) cementitious matrix resulted by the hydration and hardening of cement; (b) fillers (added in the fresh mixture); (c) interfaces between these phases. The last one i.e. the interfaces between filler particles (able to form a network of conductive phases), have the highest effect on the electrical conductivity $[12,13]$.

For this puropse, microfilters or/and nanofillers are commonly used, due to their higher potential area for connecting to one another. Several types of fillers were studied i.e. carbon fibers [1, 10, 1418], carbon nanotubes [18-24], steel fibers [25, 26], nickel powder [27, 28] and carbon black [1, 10, 29-30].

In particular, the cementitious composites containing carbon black $(\mathrm{CB})$ are found to present piezoresistive behavior; the use of $\mathrm{CB}$ particles as fillers in concrete structures has some advantages (e.g low cost, good dispersibility, accelerate the kinetic process of crystallization) for structural health monitoring applications when compared with other additives i.e. carbon fibre and carbon nanotubes [23, 29-32]. The cementitious composites containing CB nanofillers are able to sense strain through the variation of electric resistance, and therefore it can be used as sensors for nondestructive monitoring methods of infrastructures [23].

Nevertheless, the improvement of electric characteristics of the concrete should not affect its main properties (as construction material) i.e. workability of fresh mix and mechanical strengths of hardened concrete.

The main objective of this research is to develop self-sensing cementitious composites (mortars) with adequate construction properties (good workability and mechanical strength); the amount of CB used in this study was smaller as compared to one used by Monteiro et al. [29, 33] therefore it should have a smaller negative impact on the workability of fresh mortars as compared with higher $\mathrm{CB}$ dosage. In this study a non-destructive testing method was used to assess the changes in the electrical properties of mortars subjected to mechanical stress. Impedance spectroscopy (IS) is a non-destructive method used to assess the changes in setting mechanism of Portland cement, mortar and dental materials [35-42]; a correlation between the pore sizes in hardened cement paste and the impedance spectra was reported [37-40].

\section{Materials and methods}

\subsection{Materials}

In this study Portland cement CEM I 42.5R and a commercial available carbon black powder were used as raw materials.

The oxide composition of PC was assessed by chemical method presented in EN 196-2:2013 [43].

Two types of specimens were prepared:

- cement pastes without/with CB nanopowder, prepared with water to binder ratio of 0.5 ;

- mortars, with cement to aggregate ratio of 0.33 and water to binder ratio of 0.5 ; the aggregate was natural sand as described in European norm EN 196-1, part 1 [44]. The mortar specimens were cast in cuboid moulds (40x40x160mm), vibrated for $2 \mathrm{~min}$ and cured in humid air (R.H. 95\%) for 28, 90 and 180 days

The first step was to disperse carbon black powder in water, by vigorous stirring. This suspension was then mixed with the PC (and sand - in the case of mortars). CB powder was used to replace various amount of PC. Samples were coded in correlation with their content in CB nanopowder : E reference (100wt\% PC); CB0.5 - $99.5 \mathrm{wt} \% \mathrm{PC}+0.5 \mathrm{wt} \% \mathrm{CB} ; \mathrm{CB} 1-99 \mathrm{wt} \% \mathrm{PC}+1 \mathrm{wt} \% \mathrm{CB} ; \mathrm{CB} 3-$ $97 \mathrm{wt} \% \mathrm{PC}+3 \mathrm{wt} \% \mathrm{CB}$ and CB5 $-95 \mathrm{wt} \% \mathrm{PC}+5 \mathrm{wt} \% \mathrm{CB}$.

\subsection{Methods}

The PC mineralogical composition was assessed by X-ray diffraction, with a Shimadzu XRD 6000 diffractometer, with $\mathrm{Ni}$-filtered $\mathrm{CuK} \alpha$ radiation $(\alpha=1.5406 \AA), 2$ theta in $5-70^{\circ}$ range. 
The morphology of $\mathrm{CB}$ and the microstructure of mortars cured for 28, 90 and 180 days, were assessed by scanning electron microscopy (SEM). Quanta Inspect F scanning electron microscope with a Schottky emission electron beam $(1.2 \mathrm{~nm}$ resolution at $30 \mathrm{kV}$ and $3 \mathrm{~nm}$ at $1 \mathrm{kV}$ for BSE; gold coating of the samples) was used.

BET specific surface area of carbon black nanopowder was assessed by nitrogen adsorption measured as a function of relative pressure using a fully automated analyzer - Micrometrics Gemini V2 model 2380.

Flexural and compressive strengths were assessed on mortars specimens with a Matest machine, in accordance with the method presented in EN 196-1:2016 [44]; the final values were calculated as the average of minimum three strength values determined on mortars cured in similar conditions.

The mortar specimens, cured for 90 and 180 days, were also tested by AC impedance using a S1 1260 Impedance Analyzer. Impedance measurements were performed using two electrodes arrangement $(20 \times 30 \mathrm{~mm}$ at distance $40 \mathrm{~mm})$ - Figure 1a. The setup presented in Figure 1b, assess impedance from $5 \mathrm{MHz}$ down to $1 \mathrm{~Hz}$. Amplitude of the sinusoidal voltage was $1.5 \mathrm{mV}$. The loading protocol implies few steps. First step is impedance measurement without load for $7 \mathrm{~min}$. The procedure was incrementally repeated for higher pressures until the sample was broken.

The results of measurements are included in Nyquist plot shown as semicircles for sample and for electrodes. In this paper the Nyquist plot can be seen in the high-frequency region of the experimental curve as a semicircle.

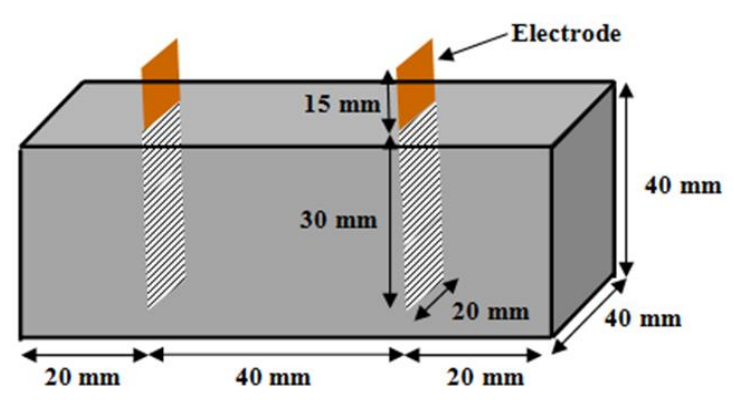

a

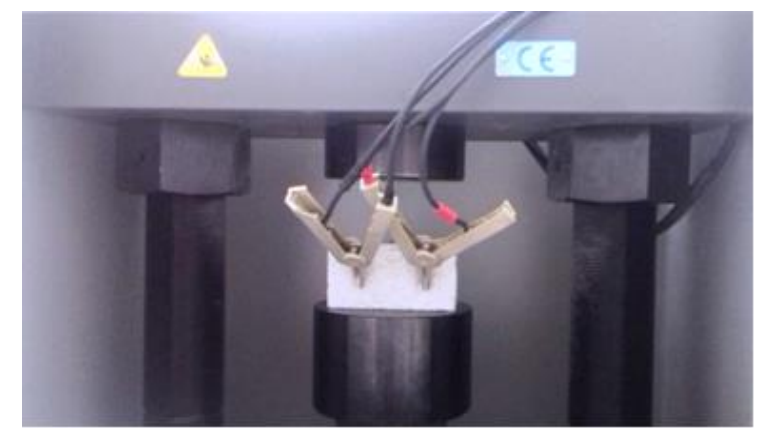

b

Figure 1. Impedance measurement under compression test: experimental set-up

The piezoresistivity tests were perfomed on mortars cured for 90 and 180 days. The loads were applied on the two ends of the mortar specimens, in the longitudinal direction of specimens (Figure 1b). The piezoresistivity of each mortar specimen is calculated by the following equation (fractional change in longitudinal variation):

$$
\frac{\Delta R}{R_{0}}=\left(\frac{R-R_{0}}{R_{0}}\right) \times 100 \%
$$

where $R$ is electrical resistance and $R_{0}$ is the initial value of electrical resistence prior to any loading.

\section{Results and discussions}

The oxide composition of PC (CEM I 42.5R) is provided in table 1.

Table 1.Oxide composition of Portland Cement

\begin{tabular}{|c|c|c|c|c|c|c|}
\hline \multicolumn{6}{|c|}{ Mass as oxide (wt $\%$ ) } & \multirow{2}{*}{ LOI (wt $\%)$} \\
\hline $\mathrm{CaO}$ & $\mathrm{SiO}_{2}$ & $\mathrm{Al}_{2} \mathrm{O}_{3}$ & $\mathrm{Fe}_{2} \mathrm{O}_{3}$ & $\mathrm{MgO}$ & $\mathrm{SO}_{3}$ & \\
\hline 63.78 & 20.12 & 4.58 & 3.99 & 1.20 & 2.61 & 3.72 \\
\hline
\end{tabular}


The mineralogical composition of PC, was assessed by X-ray diffraction; the peaks specific for the main mineralogical compounds of Portland clinker are present on the XRD patterns: alite $\left(\mathrm{Ca}_{3} \mathrm{SiO}_{5}\right.$; PDF 42-0551), belite $\left(\mathrm{Ca}_{2} \mathrm{SiO}_{4}\right.$; PDF 33-0303) and calcium aluminate $\left(\mathrm{Ca}_{3} \mathrm{Al}_{2} \mathrm{O}_{6}\right.$; PDF 33-0251).

BET specific surface area of carbon black powder is $71.83 \mathrm{~m}^{2} / \mathrm{g}$; this high specific surface area implies a high adsorption capacity of fluids (liquid or gas) on CB particles

SEM image of CB powder (Figure 2) shows the presence of spherical CB particles; the statistical processing of 150 particle diameters (measured on SEM images) suggests an average dimension of CB particles of $53 \mathrm{~nm}$.

The flexural and compressive strengths increase with the increase of curing time from 28 to 90 days - Figure 3. This is the direct results of hydration and hardening process of Portland cement. The substitution of Portland cement with small amounts of CB nanopowder (0.5-1wt.\%) do not have a major influence on the mechanical strengths values (with reference to E). The increase of carbon black nanopowder dosage (3-5wt.\%) determines a small decrease of both compressive and tensile strengths, especially at a longer curing times (90 days), most probably due to the increase of capillary porosity of mortars, due to the evaporation of water (not bound in hydrates).
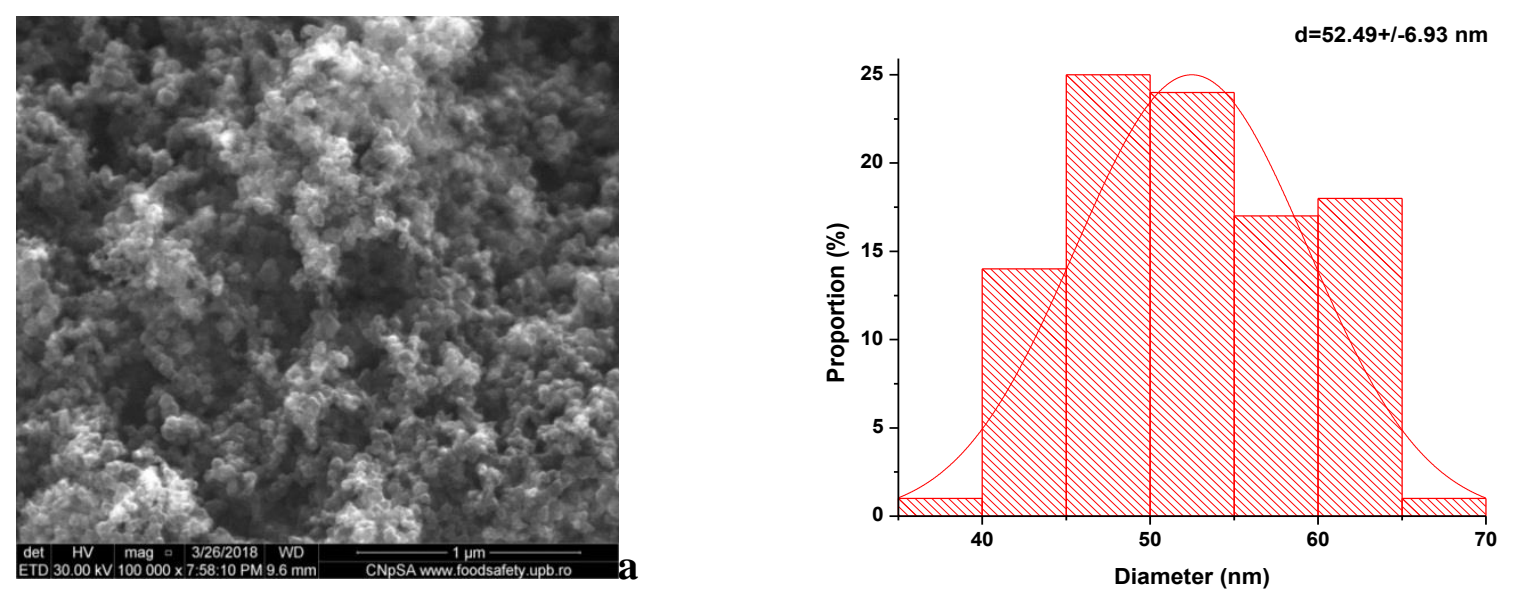

Figure 2. SEM image (a) and grain size distribution (b) of CB nanopowder

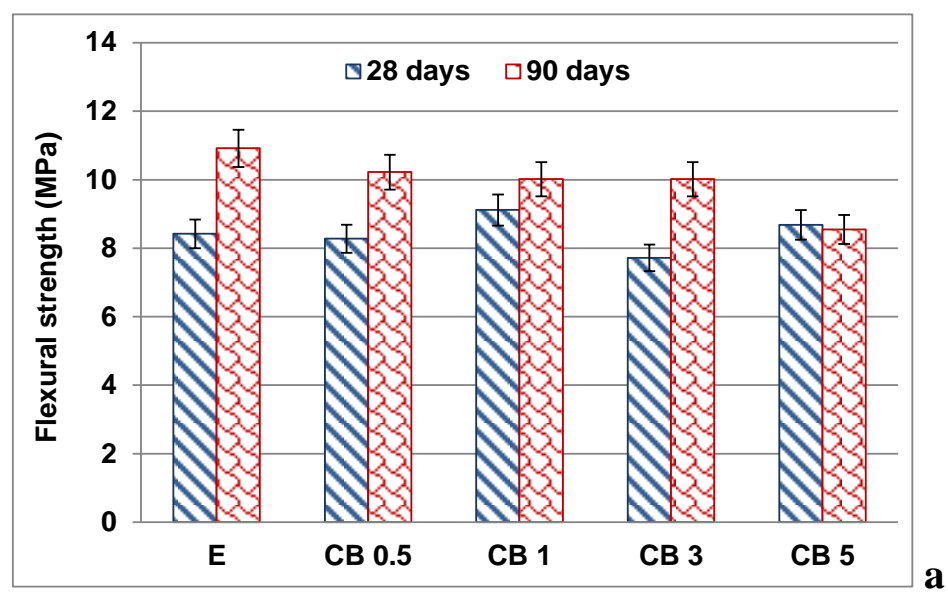




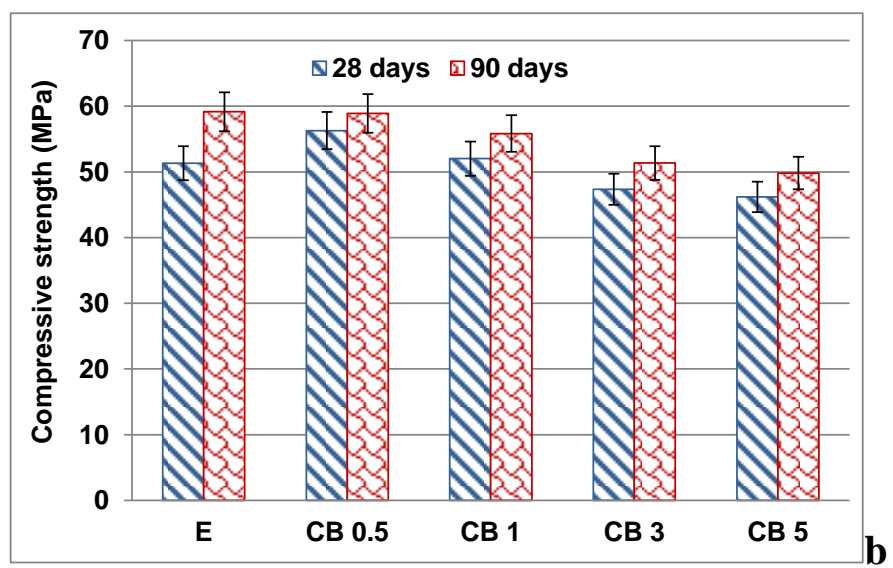

Figure 3.Variation of mechanical strength as a function of CB amount in mortars: $a$ - compressive strength, $b$ - flexural strength

SEM images of mortars cured for 28 and 90 days are presented in Figures. 4 and 5. For all studied mortars, irrespective of curing time, one can assess the presence of aggregate and phases specific for this type of material i.e.: hexagonal plates for $\mathrm{Ca}(\mathrm{OH})_{2}$, well defined needle-shaped formations characteristic to ettringite $\left(3 \mathrm{CaO} \cdot \mathrm{Al}_{2} \mathrm{O}_{3} \cdot 3 \mathrm{CaSO}_{4} \cdot 31 \mathrm{H}_{2} \mathrm{O}\right.$; Aft), fine needles and films for calcium silicate hydrates (CSH), prismatic crystals for gypsum (CS) and parallel planes forming a beam characteristic to monosulfate phase (Afm) or calcium carbonate [45]. Also a densification of cement stone and increase of hydrates sizes for longer curing times ( 90 and 180 days) can be noticed. The presence of $\mathrm{CB}$ nanoparticles determine an increase of sizes of hydrates, suggesting a positive effect exerted by $\mathrm{CB}$ powder on the cement hardening; one can conclude that $\mathrm{CB}$ nanoparticles act as nucleation sites for the hydrates resulted in cement hydration process, in good correlation with the results reported by other researchers [46-50].

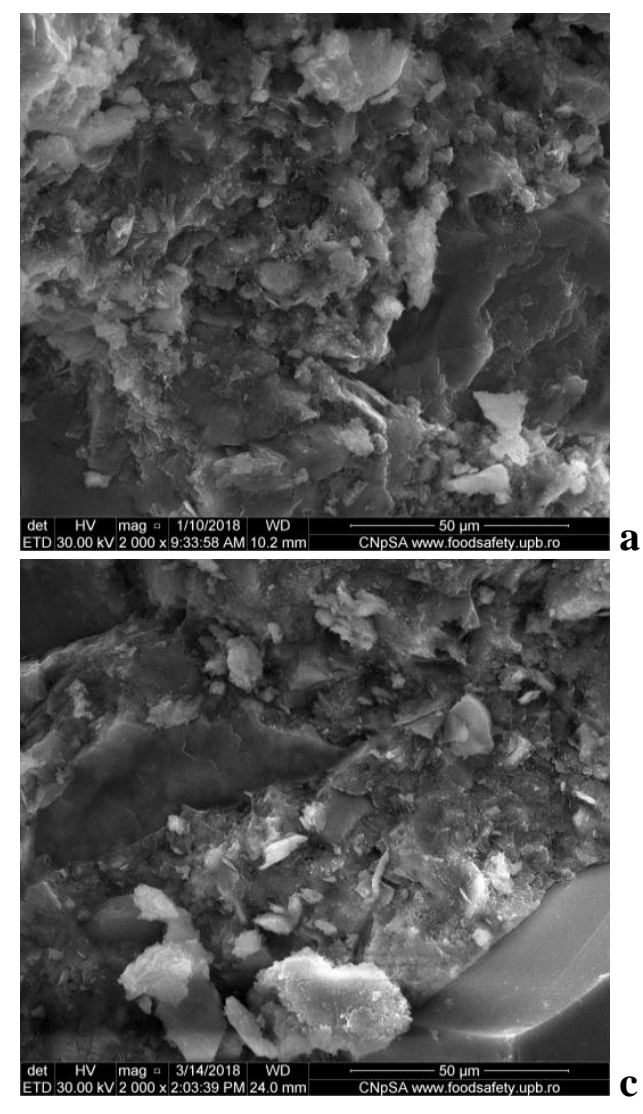

Rev. Chim., 71 (5), 2020, 30-44

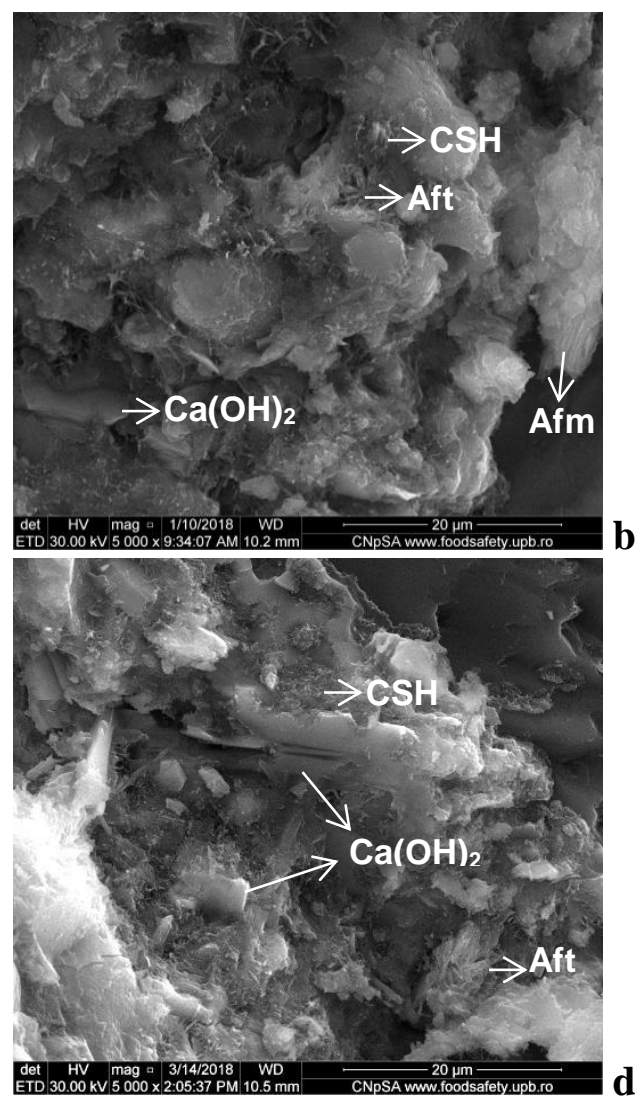

https://doi.org/10.37358/RC.20.5.8110 

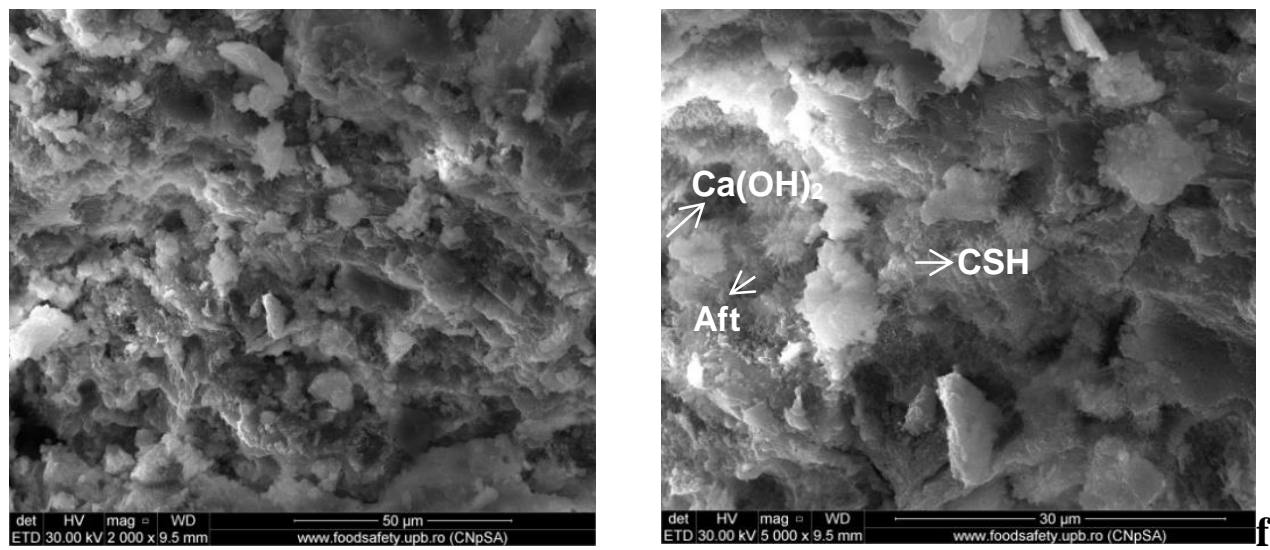

Figure 4. SEM images for $\mathrm{E}$ at 28 days (a, b), 90 days (c, d) and 180 days (e, f)
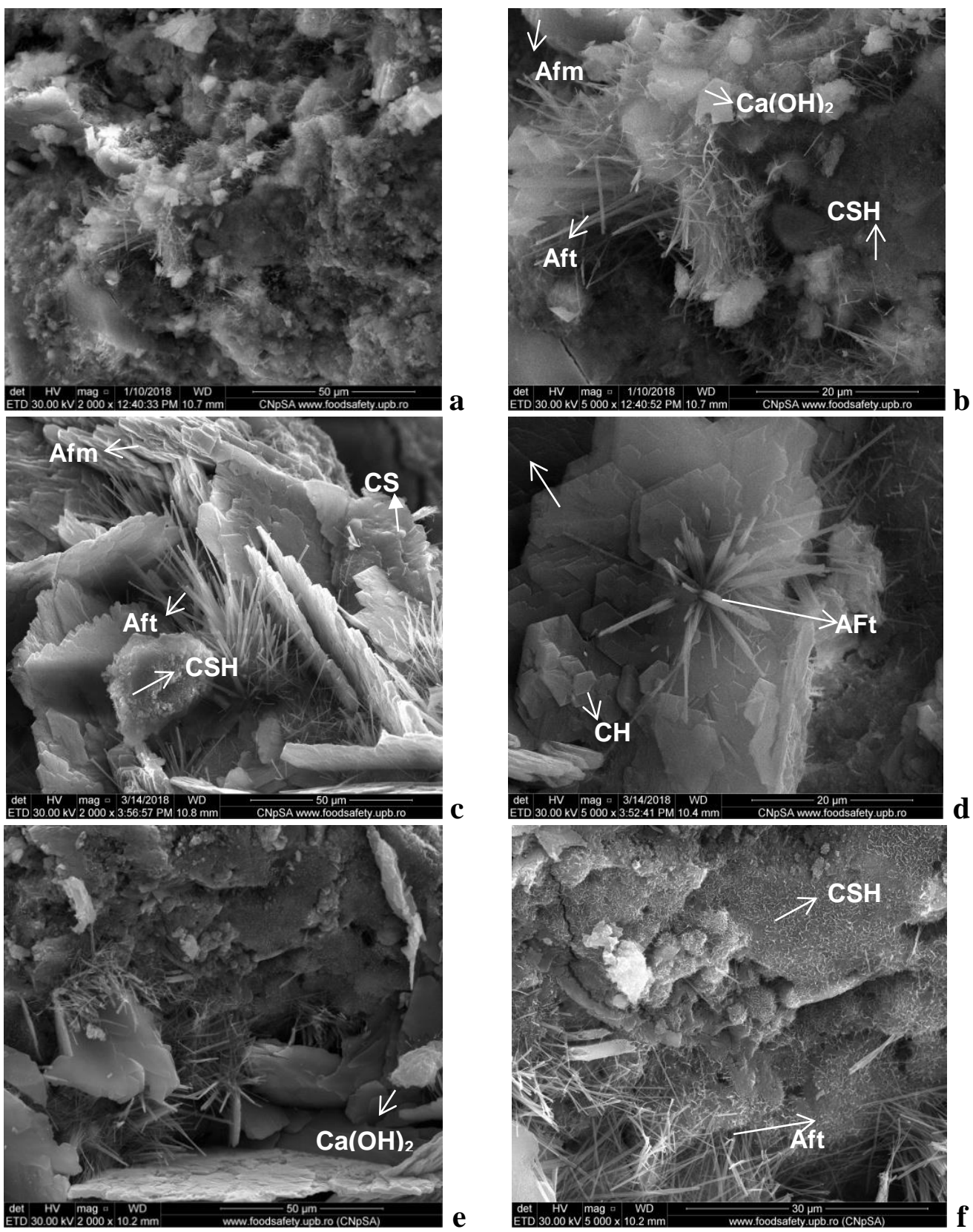

Figure 5. SEM images for CB5 at 28 days (a, b), 90 days (c, d) and 180 days (e, f) 
Since the results of the AC electrochemical impedance spectroscopy (EIS) have the same trend for all mortars with CB additions, in Figure 6 are presented, by way of example, the Nyquist plot for CB1 at different loadings and for different curing times. One may notice that all impedance spectra are composed of a semicircle which correspond to interior grain electrical resistance ( $\mathrm{Rg})$, grain boundary electrical resistance $(\mathrm{Rgb})$ and electrodes contribution.

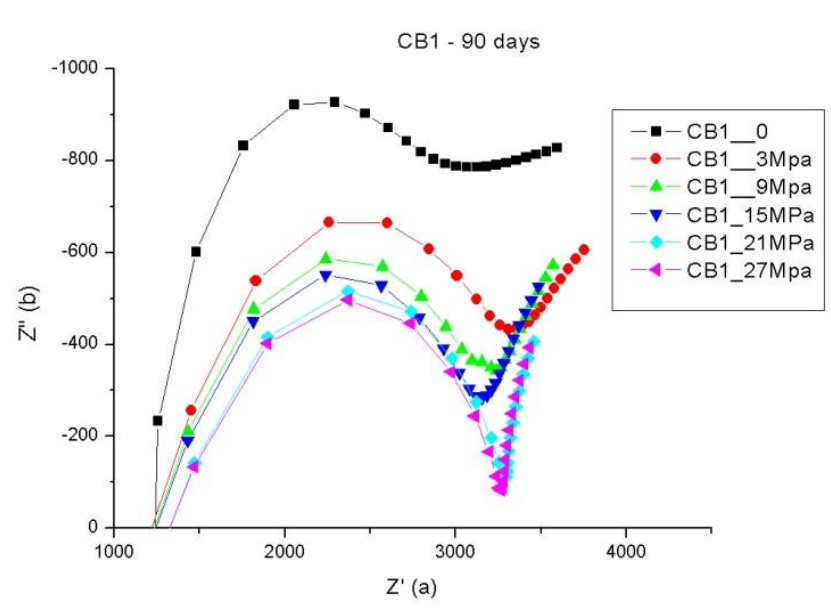

a

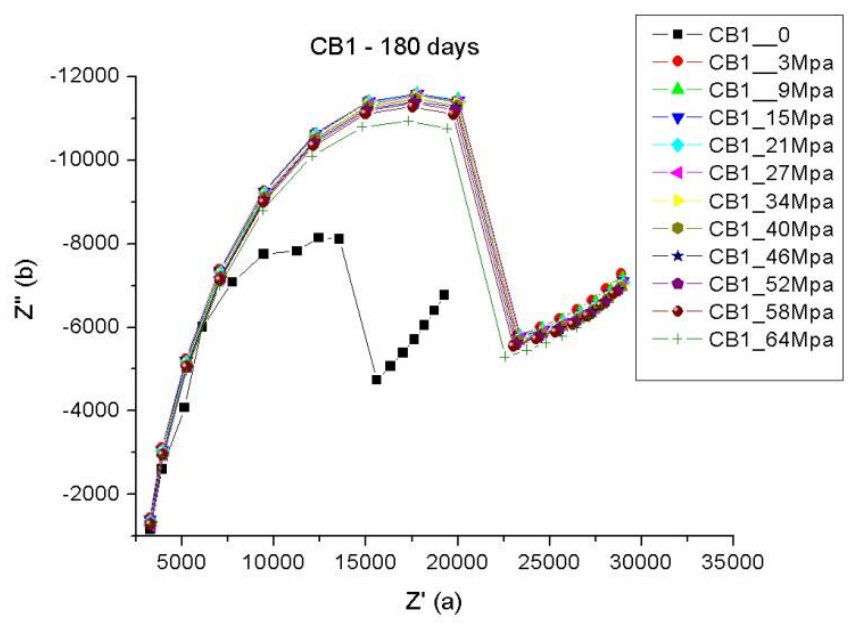

b

Figure 6. Complex impedance plots for mortars with $1 \% \mathrm{CB}$ addition cured for

a) 90 and b) 180 days (Black- without load)

This type of impedance plots fits to the conventional equivalent circuit (Figure 7), formed by a series of two sub-circuits of parallel resistors (R) and constant phase elements (CPE). The constant phase elements are used to accommodate the non-ideal behavior of the capacitance, which could be due to the presence of more than one relaxation process with similar relaxation times. CPEg represents the constant phase element for grain interior and CPEgb is the constant phase element for grain boundaries.

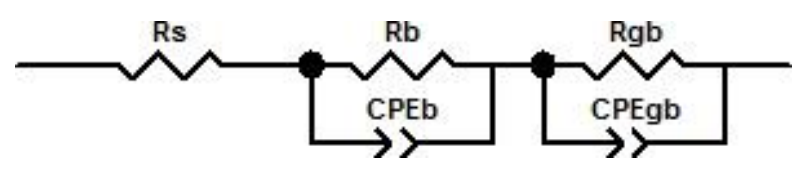

Figure 7. Equivalent circuit

Figure 8 shows the resistivity of binding masses as a function of CB quantity for different ages in the absence of loading. For the same period of hardening it can be observed that the resistivity decreases significantly when $\mathrm{CB}$ content exceded $0.5 \%$. For values greater than $1 \%$ the resistivity continuos to decrease but the slop become smaller. One can estimate that the percolation threshold of the composites was in the domain of $0.5-1 \%$. Also, it must be underlined that the same trend is evident for all the investigated times of hardening but the values of resistivities increased with ages. In addition one may noticed that percolation threshold zone was observed at a lower content in CB than that reported by $\mathrm{H}$. Li at al. [51]. 


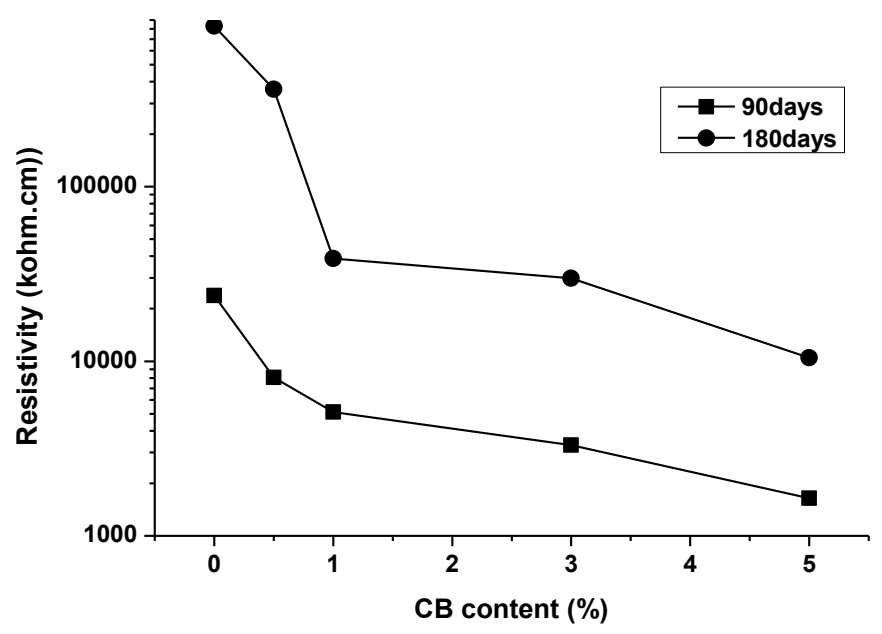

Figure 8. Logarithm of resistivity as a function of $\mathrm{CB}$ content for different age in the absence of loading

Electrical resistivity increase continuously with extended curing, for all studied compositions. This can be explained by the structural and morphological modification taking place in these materials. Electrical resistivity of concrete is related to porosity, tortuosity of the pore network as well as the composition and amount of pore solution [52]. Changes of these parameters can modify the electrical properties of the material (the evaporation of water from the system, the increase of the cristallinity of formed hydrates, shrinkage, strain-stress effect, dispertion of the conducting phase).

In Figure 9 is presented the electrical resistance components (intragranular-Rg and intergranular$\mathrm{Rgb}$ ) as a function of $\mathrm{CB}$ content, in the absence of the loading. As it can be seen, Rgb has a major influence on the electrical behaviour of the mortars. The structure of the interfacial tranzition zone (ITZ) between agregate and cement paste, has a major influence on the concrete or mortar properties [53]. This zone, often said to be 50 micrometer in thickness, determines the weakness of the composite materials [54]. Cracks propagate preferentially along ITZ and water can easily penetrate or be released; therefore, after hardening ITZ will contain large cristals and will have a higher porosity in comparison with the bulk cement paste [55-57].

The increase of size and crystalinity degree of hydrates formed during the cement hydration, especially at longer curing times - 180 days (Figures 4 and 5) has an important impact on the $\operatorname{Rg}$ and $\mathrm{Rgb}$ values. As expected, the increase of $\mathrm{CB}$ content induced a significant decrese of electrical resistance values in the intergranular area infering the idea that the small CB particles are localized in this zone, in good agreement with the percolation treshold domain establised above.

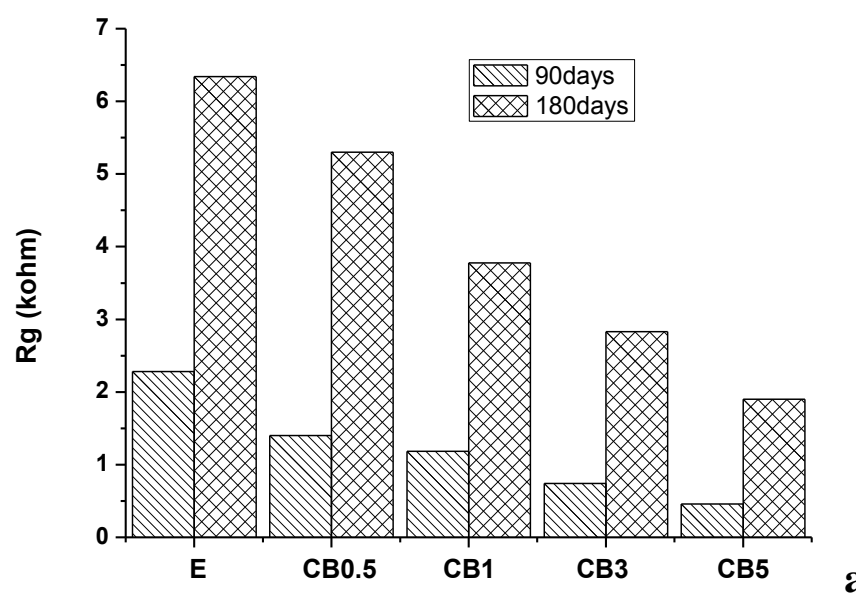




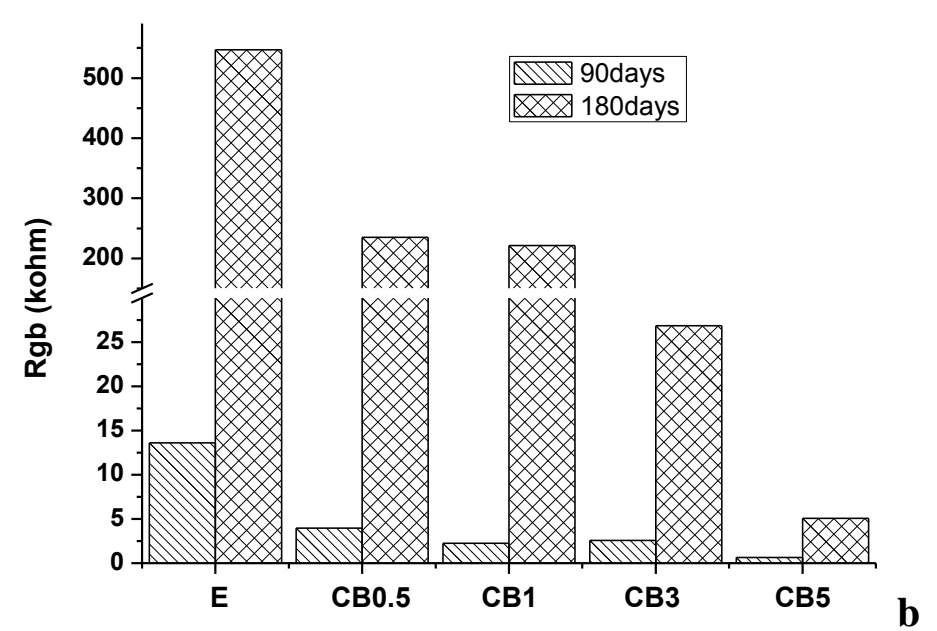

Figure 9. Intragranular (a) and intergranular (b) resistance for mortars cured for 90 and 180 days, assessed in the absence of loading

The values of both components of the electrical resistance ( $\mathrm{Rg}$ and $\mathrm{Rgb}$ ) decreases with the increase of CB nanopowder amount. In the case of mortars cured for 90 days (Figure 9a), intragranular resistance $(\mathrm{Rgb})$ presents a narrow variation domain $(0.5-2 \mathrm{k} \Omega)$ while this variation is wider after 180 days of curing (1.8-6.5 k $\Omega$ )- Figure $9 \mathrm{~b}$.

This phenomenon is more intense for granules boundaries zone. Is evident that, after 180 days of curing, one can notice a large domain of variation of intergranular electrical resistance - from $550 \mathrm{k} \Omega$ for $\mathrm{E}$ (CB free) to $5.5 \mathrm{k} \Omega$ for CB5 (with $5 \mathrm{wt} \% \mathrm{CB}$ amount). At 90 days, the cement hydration and hardening processes are still in progress, while after 180 days of curing a plateau is reached: the water content is diminished (due to consumption in hydrates formation or evaporation), and the amount of solution in pores decrease. On the other hand, CB particles form conductive networks at increase significantly with concentration. Their role as catalysts in promoting hydration reactions should also not be omitted.

As a conclusion, one may underline that electrical resistance of the mortars increases in time and is very much influenced by the $\mathrm{CB}$ amount. At the same time it is evident that intergranular component of electrical resistance ( $\mathrm{Rgb}$ ) is determinant for the electrical behaviour.

The electrical resistance (calculated as $\mathrm{Rg}+\mathrm{Rgb}$ ) of cement-based composites, without and with four different CB contents, are shown in Figure 10.

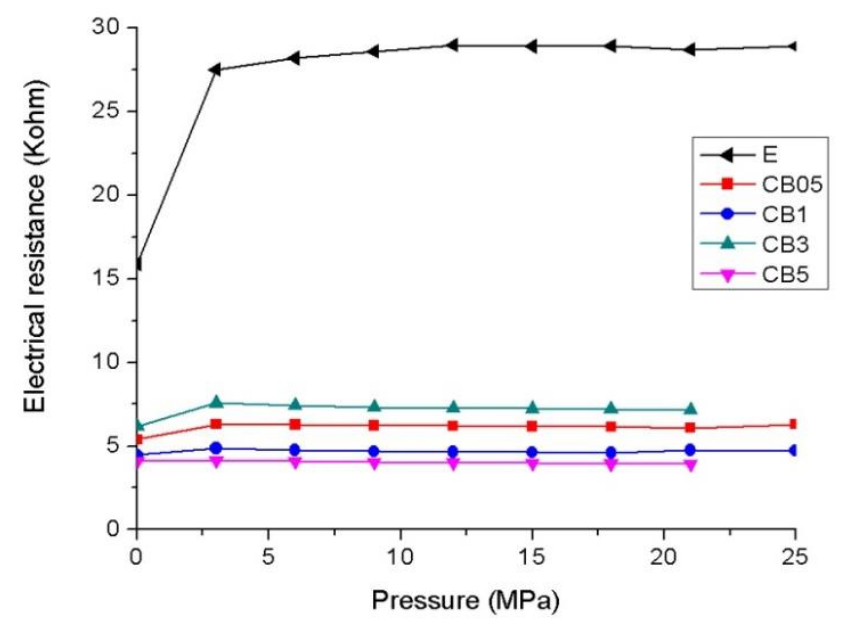




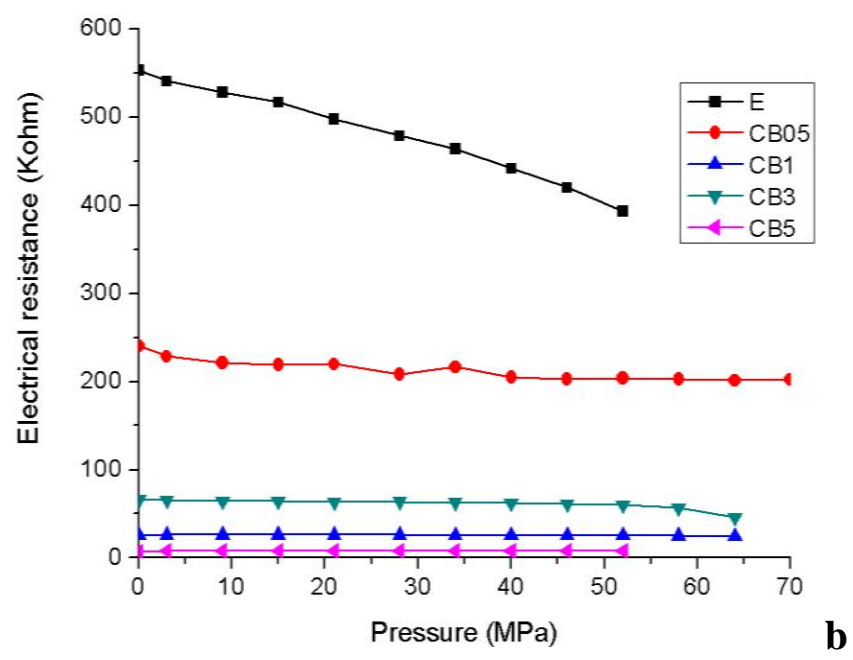

Figure 10. Variation of total electrical resistance $(\mathrm{Rg}+\mathrm{Rgb})$

vs loading pressure for different CB amounts cured 90 days (a) and 180 days (b)

The electrical resistance of mortars cured for 180 days (Figure 10b), decreases with the increase of $\mathrm{CB}$ concentration, from $553.2 \mathrm{k} \Omega$ for sample $\mathrm{E}$ to $6.8 \mathrm{k} \Omega$ for $\mathrm{CB} 5$ (no loading pressure). When load is applied, a significant decrease of the electrical resistance for reference mortar $\mathrm{E}$ is evident and a more reduce variations when $\mathrm{CB}$ is present in mortar.

CB free mortar cured for 90 days, has a different behavior vs. loading pressure (Figure 10a); the electrical resistance has a sharp increase after the first step (pressure increase from 0 to $3 \mathrm{MPa}$ ) i.e. from $1.5 \mathrm{k} \Omega$ to $27 \mathrm{k} \Omega$, and remain almost unchanged when the load varies up to $25 \mathrm{MPa}$.

At $\mathrm{CB}$ concentrations close to percolation threshold (0.5-1 wt.\% CB), the filler forms a continuous conducting network. It's been proven that tunneling currents between closely separated particles play a major role in the mechanism of conductivity. The change of conductivity is connected with both - the breakdown and recombination of electro conductive network paths and the change of intensity of the tunneling currents.

The ratio of the grain boundary resistance to the total resistance ( $\mathrm{Rgb} /(\mathrm{Rg}+\mathrm{Rgb})$, represents the so called blocking factor (BF). In Figure 11 the variation of this factor at different loads for the samples with various $\mathrm{CB}$ content is presented. $\mathrm{BF}$ values decrease significantly with the increase of $\mathrm{CB}$ concentration in mortars and one can notice 3 main compositional domains : i) $0-0.5 \mathrm{wt} \% \mathrm{CB}$, ii) $1-3$ wt $\% \mathrm{CB}$ and iii) $5 \mathrm{wt} \%$.

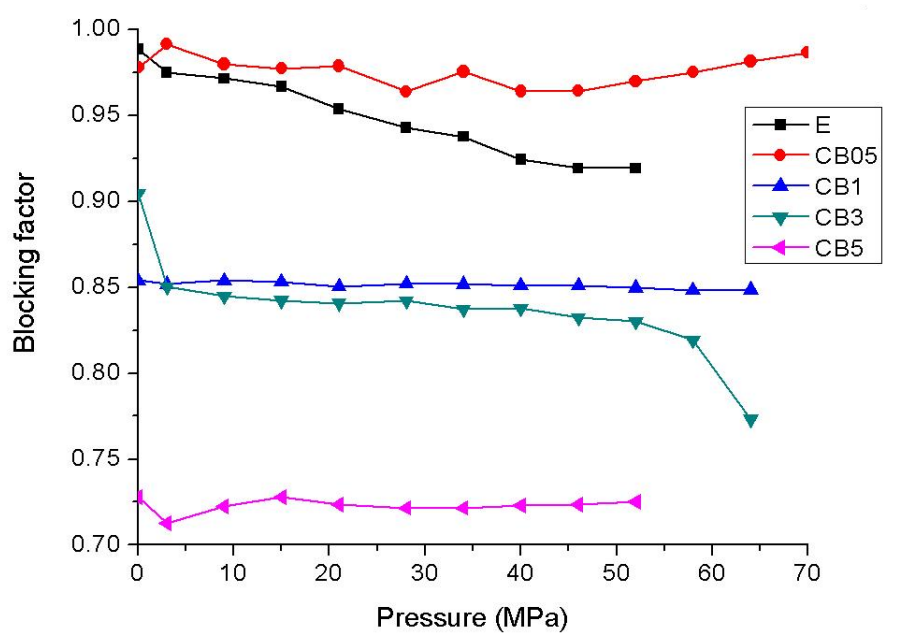

Figure 11. Blocking factor $(\mathrm{BF})$ variations vs loading pressure for mortars cured for 180 days and with different CB amount 
It can be observed from BF values presented in Figure 11, that loading pressure has no significant influence when the $\mathrm{CB}$ amount is constant.

The influences of the $\mathrm{CB}$ content in mortar composition, curing time and loading pressure on the piezoresistivity values are presented in Figure 12.

It is important to mention that electrical resistivity of this type of composites has major changes when the curing time increases from 90 to 180 days; in case of mortars cured 90 days, the fractional change in longitudinal variation of mortars vs. load pressure is mainly negative for all samples with different $\mathrm{CB}$ content, in the investigated domains of pressure (Figure 12a). Only after the first load (from 0 to $3 \mathrm{MPa}$ ) is applied the electrical resistance presents a sharp increase and the fractional change is positive. Positive piezoresistivity means that electrical resistance increases with increasing strain, e.g. $(\mathrm{dR} / \mathrm{R})>0$ and negative piezoresistivity means that electrical resistance decreases with increasing strain, e.g. $(\mathrm{dR} / \mathrm{R})<0$. Positive piezoresistivity may be explained by the changes of mortar microstructure so that the electrical resistance increases in the direction of the deformation. In our case the distance between adjacent conductive particles (CB) increases upon deformation of the stiff material (hardened mortar), thereby decreasing the chance of direct contact between CB particles. On the contrary, negative piezoresistivity represents the improvement of the conductance upon load, thereby the contact area between conductive CB particles increases.

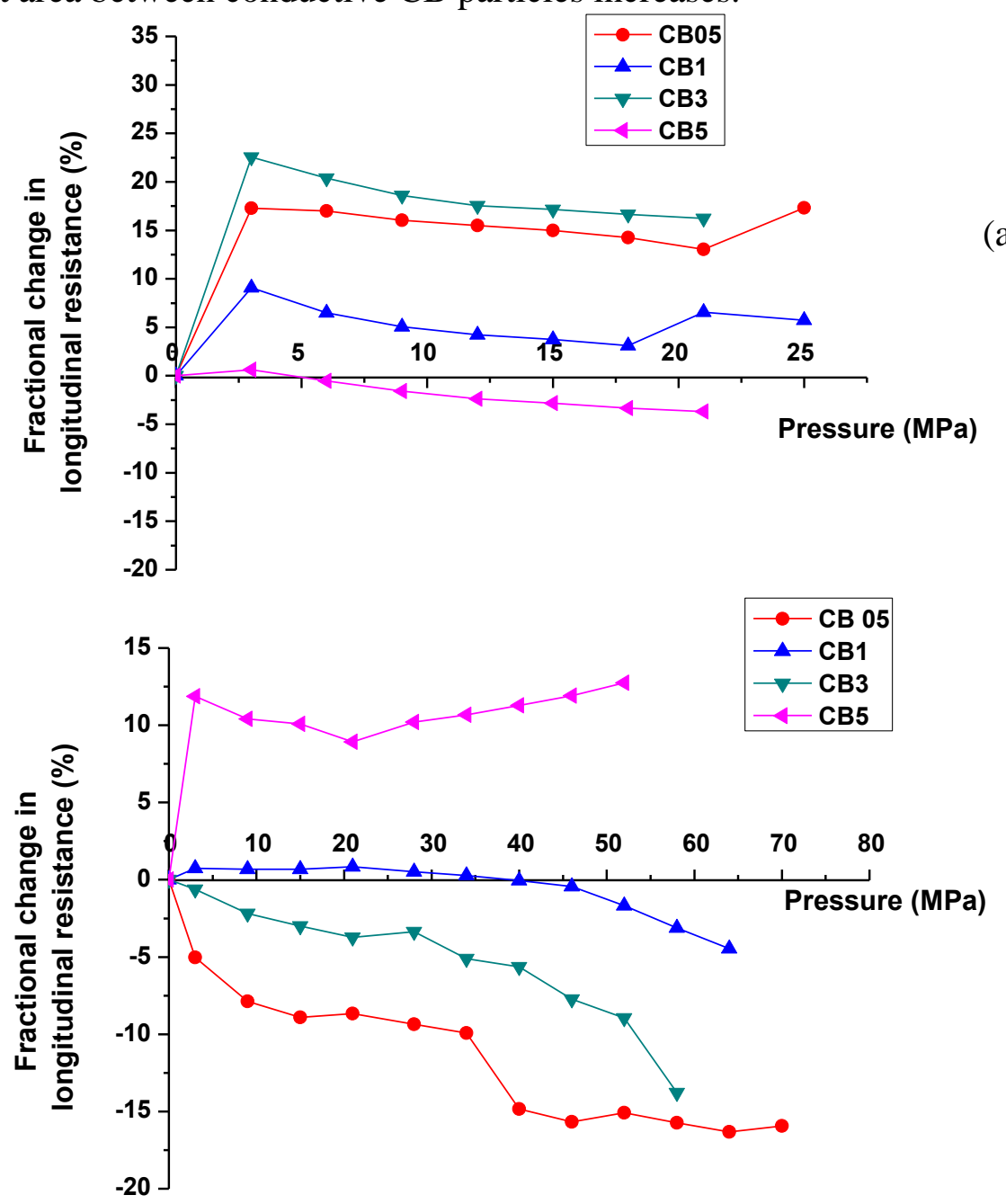

Fig. 12. Fractional change in longitudinal resistance (\%) vs. loading pressure $(\mathrm{MPa})$ for mortars with different $\mathrm{CB}$ amounts cured for: a) 90 days and b) 180 days 
For the mortars cured longer times (180 days - Fig.12b) one may observe that almost all mortars have negative piezorezitivity, except the mortar with the higher $\mathrm{CB}$ content $(5 \mathrm{wt} . \%)$. One possible explanation for this unexpected result can be connected with the effect determined by CB nanoparticles on the nucleation and growth of hydrates formed by cement hydration. As previously presented, the amount and size of hydrate phases increases when CB is present in the system, because $\mathrm{CB}$ nanoparticles can act as nucleation sites for hydrates; for higher CB dosage (over $3 \mathrm{wt} . \%$ ) the amount and size of hydrates formed at the surface of $\mathrm{CB}$ particles will become higher, therefore preventing the contact between conductive $\mathrm{CB}$ particles even at the increase of the load pressure. For self-sensing materials, is necessary to have a large fractional change in electrical resistance per unit strain. In order to obtain a large fractional change in resistance at a particular strain, both positive and negative piezoresistivities are useful in order to provide a high magnitude of the fractional change in resistance. For stiff structural materials (such as mortar or concrete) the strain is small, therefore the fractional change in electrical resistance is essentially equal to the fractional change in longitude variation.

From this point of view, for the studied composites, the best results were obtained for the mortars with 0.5-3 wt.\% CB cured for 180 days.

\section{Conclusions}

The experimental results presented in this article demonstrate that carbon black nanopowder can be successfully incorporated in cement-based matrices, in order to reduce their electrical resistance. The presence of CB (0.5-5 wt.\%) in mortars do not have an important negative effect on mechanical properties (i.e. strength losses).

In all mortars, irrespective of curing time, one can observe the presence of specific hydrated phases formed by Portland cement hydration.

AC electrochemical impedance spectroscopy (EIS) observations demonstrates the major influence of intergranular electrical resistance $(\mathrm{Rgb})$ on the electrical behavior (piezorezistivity) of the investigated mortars.

The values of electrical resistance are strongly correlated with the composition, morphology and curing time of the mortars. In this study significant changes of the electrical behaviour (piezorezistivity) of the mortars vs. curing time (90 or 180 days) were noticed so this must be considered in practical applications when aiming to monitor parameters such as stress, strain, cracking and damage.

The monitoring of the electric resistance change of mortars with $\mathrm{CB}$ additions, could give information regarding their damage degree. From the point of view of $\mathrm{CB}$ dosage, the best results (for electrical properties) were obtained for the mortars with $0.5-3 \mathrm{wt} . \% \mathrm{CB}$.

Acknowledgement. The work has been funded by the Operational Programme Human Capital of the Ministry of European Funds through the Financial Agreement 51668/09.07.2019, SMIS code 124705.

\section{References}

1.DING, Y., CHEN, Z., HAN, Z., ZHANG, Y., PACHECO-TORGAL, F., Nano-carbon black and carbon fiber as conductive materials for the diagnosing of the damage of concrete beam, Constr. Build. Mater. 43 (2013), p.233-241. doi:10.1016/j.conbuildmat.2013.02.010.

2.SONG, G., MO, L.Y., OTERO, K., GU, H., Health monitoring and rehabilitation of a concrete structure using intelligent materials, Smart Mater. Struct. 15 (2006), p.309-314. doi:10.1088/09641726/15/2/010.

3.LI, H., LI, D., SONG, G., Recent applications of fiber optic sensors to health monitoring in civil engineering, 26 (2004), p.1647-1657. doi:10.1016/j.engstruct.2004.05.018.

4.WANG, C.S., WU, F., CHANG, F., Structural health monitoring from fiber-reinforced composites to steel-reinforced concrete, $\mathbf{5 4 8}$ (2001). 
5.CHANG, P.C., FlATAU, A., LIU, S.C., Structural Health Monitoring Review Paper: Health Monitoring, (2014). doi:10.1177/1475921703036169.

6.MONTEIRO, A.O., CACHIM, P.B., COSTA, P.M.F.J., Self-sensing piezoresistive cement composite loaded with carbon black particles, Cem. Concr. Compos. (2017). doi:10.1016/j. cemconcomp.2017.04.009.

7.ALAVI, A.H., HASNI, H., LAJNEF, N., CHATTI, K., Continuous health monitoring of pavement systems using smart sensing technology, Constr. Build. Mater. 114 (2016), p.719-736. doi:10.1016/j.conbuildmat.2016.03.128.

8.SIAD, H., LACHEMI, M., SAHMARAN, M., MESBAH, H.A., ANWAR, K., Advanced engineered cementitious composites with combined self-sensing and self-healing functionalities, Constr. Build. Mater. 176 (2018), p.313-322. doi:10.1016/j.conbuildmat.2018.05.026.

9.HAN, B., OU, J., Embedded piezoresistive cement-based stress / strain sensor, 138 (2007) p.294298. doi:10.1016/j.sna.2007.05.011.

10.LOAMRAT, K., SAPPAKITTIPAKORN, M., SUKONTASUKKUL, P., BANTHIA, N., Effect of Carbon Fiber and Graphite Powder on Resistivity of Cement-based Sensor under Compression, KMUTNB Int. J. Appl. Sci. Technol. 7 (2014) p.29-35. doi:10.14416/j.ijast.2014.01.005.

11.ZHU, S., CHUNG, D.D.L., Analytical model of piezoresistivity for strain sensing in carbon fiber polymer - matrix structural composite under flexure, 45 (2007) p.1606-1613. doi:10.1016/j. carbon.2007.04.012.

12.HAN, B., DING, S., YU, X., Intrinsic self-sensing concrete and structures: A review, Measurement. 59 (2015) p.110-128. doi:10.1016/j.measurement.2014.09.048.

13.MEHTA, K.P., MONTEIRO, P.J.M., Concrete: Microstructure, Properties, and Materials, 3rd ed, McGraw-Hill Publishing, New York, 2006. doi:10.1036/0071462899.

14.AZHARI, F., BANTHIA, N., Carbon fiber-reinforced cementitious composites for tensile strain sensing, Amer. Conc. I. 114 (2017) p.129-136. doi:10.14359/51689486.

15.CHEN, B., Conductivity of carbon fiber reinforced cement-based composites, 26 (2004) p.291-297. doi:10.1016/S0958-9465(02)00138-5.

16.CHEN, P.W., CHUNG, D.D.L., Carbon fiber reinforced concrete for smart structures capable of non-destructive flaw detection, Smart Mater. Struct. 22 (1993) p.22-30. doi:http://iopscience.iop. org/0964-1726/2/1/004.

17.GAY, C., SANCHEZ, F., Performance of Carbon Nanofiber - Cement Composites with a HighRange Water Reducer, (2010) 109-113. doi:10.3141/2142-16.

18.ANIL, Ö., Piezoresistive behavior of CF- and CNT-based reinforced concrete beams subjected to static flexural loading: Shear failure investigation, 168 (2018) p.266-279. doi:10.1016/j.conbuildmat. 2018.02.124.

19.ALESSANDRO, A.D., RALLINI, M., UBERTINI, F., MATERAZZI, A.L., Investigations on scalable fabrication procedures for self-sensing carbon nanotube cement-matrix composites for SHM applications, 65 (2016) p.200-213. doi:10.1016/j.cemconcomp.2015.11.001.

20.KONSTA-GDOUTOS, M.S., AZA, C.A., Cement \& Concrete Composites Self sensing carbon nanotube ( CNT ) and nanofiber ( CNF ) cementitious composites for real time damage assessment in smart structures, Cem. Concr. Compos. 53 (2014) p.162-169. doi:10.1016/j.cemconcomp. 2014.07.003.

21.PARVEEN, S., RANA, S., FANGUEIRO, R., CONCEIÇÃO, M., Cement and Concrete Research Microstructure and mechanical properties of carbon nanotube reinforced cementitious composites developed using a novel dispersion technique, Cem. Concr. Res. 73 (2015) p.215-227. doi:10.1016/j.cemconres.2015.03.006.

22.HAN, B., ZHANG, K., BURNHAM, T., KWON, E., YU, X., Integration and road tests of a selfsensing CNT concrete pavement system for traffic detection, 015020 (2013). doi:10.1088/09641726/22/1/015020. 
23.HAN, B., YU, X., OU, J., Self-sensing concrete in smart structures, Butterworth Heinemann. (2014). doi:https://doi.org/10.1016/C2013-0-14456-X.

24.CHUNG, D.D.L., Piezoresistive Cement-based Materials for Strain Sensing, Compos. Mater. 13 (2002) p.599-609. doi:10.1106/104538902031861.

25.SUN, M., LIEW, R.J.Y., ZHANG, M., LI, W., Development of cement-based strain sensor for health monitoring of ultra high strength concrete, Constr. Build. Mater. 65 (2014) p.630-637. doi:10.1016/j.conbuildmat.2014.04.105.

26.TEOMETE, E., ILKIM, O., Tensile strain sensitivity of steel fiber reinforced cement matrix composites tested by split tensile test, Constr. Build. Mater. 47 (2013) p.962-968. doi:10.1016/j.conbuildmat.2013.05.095.

27.HAN, B.G., HAN, B.Z., OU, J., Experimental study on use of nickel powder-filled Portland cement-based composite for fabrication of piezoresistive sensors with high sensitivity, Sens. Actuat APhys. 149 (2009) p.51-55. doi:https://doi.org/10.1016/j.sna.2008.10.001.

28.HAN, B., HAN, B.Z., YU, X., OU, J., Ultrahigh pressure-sensitive effect induced by field emission at sharp nano-tips on the surface of spiky spherical nickel powders, Sens. Lett. 9 (2011) p.1629-1635. doi:https://doi.org/10.1166/s1.2011.1719.

29.MONTEIRO, A.O., CACHIM, P.B., COSTA, P.M.F.J., Electrical properties of cement-based composites containing carbon black particles, Mater. Today Proc. 2 (2015) p.193-199. doi:10.1016/j.matpr.2015.04.021.

30.AL-DAHAWI, A., ÖZTÜRK, O., EMAMI, F., YILDIRIM, G., SAHMARAN, M., Effect of mixing methods on the electrical properties of cementitious composites incorporating different carbonbased materials, 104 (2016) 160-168. doi:10.1016/j.conbuildmat.2015.12.072.

31.DONNINI, J., BELLEZZE, T., CORINALDESI, V., Mechanical, electrical and self-sensing properties of cementitious mortarscontaining short carbonfibers, J. Build. Eng. 20 (2018) p.8-14. https://doi.org/10.1016/j.jobe.2018.06.011.

32.AL-DAHAWI, A., YILDIRIM, G., ÖZTÜRK, O., ŞAHMARAN, M., Assessment of self-sensing capability of Engineered Cementitious Composites within the elastic and plastic ranges of cyclic flexural loading, Constr. Build. Mater. 145 (2017) p.1-10. doi:10.1016/j.conbuildmat.2017.03.236.

33.MONTEIRO, A.O., LOREDO, A., COSTA, P.M.F.J., OESER, M., CACHIM, P.B., A pressuresensitive carbon black cement composite for traffic monitoring, Constr. Build. Mater. 154 (2017) 1079-1086. doi:10.1016/j.conbuildmat.2017.08.053.

34.SHI, L., LU, Y., BAI, Y., Mechanical and electrical characterisation of steel fiber and carbon black engineered cementitious composites, 188 (2017) p.325-332. doi:10.1016/j.proeng.2017.04.491.

35.SHI, T., ZHENG, L., XU, X., Evaluation of alkali reactivity of concrete aggregates via AC impedance spectroscopy, Constr. Build. Mater. 145 (2017) p.548-554. doi:10.1016/j.conbuildmat. 2017.04.053.

36.TANG, S.W., CAI, X.H., ZHOU, W., SHAO, H.Y., HE, Z., LI, Z.J., JI, W.M., CHEN, E., In-situ and continuous monitoring of pore evolution of calcium sulfoaluminate cement at early age by electrical impedance measurement, 117 (2016) p.8-19. doi:10.1016/j.conbuildmat.2016.04.096.

37.DE VERA, G., CLIMENT, M.A., SÁNCHEZ, I., Impedance spectroscopy as a tool to study modifications in the microstructure of concrete in ionic migration experiments, WIT Trans. Eng. Sci. 57 (2007) p.135-144. doi:10.2495/MC070141.

38.CABEZA, M., KEDDAM, M., NÓVOA, X.R., SÁNCHEZ, I., TAKENOUTI, H., Impedance spectroscopy to characterize the pore structure during the hardening process of Portland cement paste, Electrochim. Acta. 51 (2006) p.1831-1841. doi:10.1016/j.electacta.2005.02.125.

39.CABEZA, M., MERINO, P., MIRANDA, A., NÓVOA, X.R., SANCHEZ, I., Impedance spectroscopy study of hardened Portland cement paste, Cem. Concr. Res. 32 (2002) p.881-891. doi:10.1016/S0008-8846(02)00720-2.

40.KIM, S.M., HWANG, J.H., Application of impedance spectroscopy to cement-based materials: hydration of calcium phosphate bone cements, J. Korean Ceram. Soc. 43 (2006) p.156-161. 
doi:https://doi.org/10.4191/kcers.2006.43.3.156.

41.STARČUKOVÁ, J., STARČUK, Z., HUBÁLKOVÁ, H., LINETSKIY, I., Magnetic susceptibility and electrical conductivity of metallic dental materials and their impact on MR imaging artifacts, Dent. Mater. 24 (2008) 715-723. doi:10.1016/j.dental.2007.07.002.

42.MOGUŠ-MILANKOVIĆ, A., SKLEPIĆ, K., ČALOGOVIĆ, M., MARCIUŠ, M., PRSKALO, K., JANKOVIĆ, B., TARLE, Z., Impedance as a measure of setting reaction in glass ionomer cements, J. Non. Cryst. Solids. 389 (2014) p.93-103. doi:10.1016/j.jnoncrysol.2014.02.012.

43.***EN 196-2.Part 2. Testing methods for cements - Part 2: Chemical analysis of cement, 2013.

44.***EN 196-1, Part 1. Methods of testing cement - Part 1: Determination of strength, 2006.

45.CAMPBELL, D.H., Microscopical examination and interpretation of Portland cement and clinker, Second Edi, Portland Cement Association, 1999.

46.SOBOLKINA, A., MECHTCHERINE, V., BERGOLD, S.T., NEUBAUER, J., BELLMANN, C., KHAVRUS, V., OSWALD, S., LEONHARDT, A., RESCHETILOWSKI, W., Effect of carbon based materials on the early hydration of tricalcium silicate., J. Am. Ceram. Soc. 99 (2016) p.21812196.

47.LEE, B.Y., KURTIS, K.E., Influence of $\mathrm{TiO}_{2}$ Nanoparticles on Early $\mathrm{C}_{3} \mathrm{~S}$ Hydration, 3405 (2010). doi:10.1111/j.1551-2916.2010.03868.x.

48.CHEN, J., KOU, S., POON, C., Cement \& Concrete Composites Hydration and properties of nano$\mathrm{TiO}_{2}$ blended cement composites, Cem. Concr. Compos. 34 (2012) p.642-649. doi:10.1016/j. cemconcomp.2012.02.009.

49.ZANFIR, A.-V., VOICU, G., BADANOIU, A.-I., GOGAN, D., OPREA, O., Synthesis and characterization of titania-silica fume composites and their in fl uence on the strength of self-cleaning mortar, 140 (2018) p.157-163. doi:10.1016/j.compositesb.2017.12.032.

50.SENFF, L., LABRINCHA, J.A., FERREIRA, V.M., HOTZA, D., REPETTE, W.L., Effect of nanosilica on rheology and fresh properties of cement pastes and mortars, Constr. Build. Mater. 23 (2009) p.2487-2491. doi:10.1016/j.conbuildmat.2009.02.005.

51.LI, H., XIAO, H., OU, J., Effect of compressive strain on electrical resistivity of carbon black-filled cement-based composites, 28 (2006) p.824-828. doi:10.1016/j.cemconcomp.2006.05.004.

52.SPRAGG, R., BU, Y., SNYDER, K., BENTZ, D., WEISS, J., Electrical testing of cement-based materials: role of testing techniques, sample conditioning, and accelerated curing, in: Publ. FHWA/IN/JTRP-2013/28, Joint Transportation Research Program, Indiana Department of Transportation and Purdue University, West Lafayette, Indiana, n.d. doi:http://dx.doi.org/ $10.5703 / 1288284315230$.

53.KONG, L., HOU, L., BAO, X., Application of AC impedance technique in study of lightweight aggregate-paste interface, Constr. Build. Mater. 82 (2015) p.332-340. doi:10.1016/j. conbuildmat. 2015.02.079.

54.SCRIVENER, K.L., TECHNIK, D.B., The Interfacial Transition Zone ( ITZ ) Between Cement Paste and Aggregate, (2004) p.411-421.

55.PROKOPSKI, G., HALBINIAK, J., Interfacial transition zone in cementitious materials, Cem. Concr. Res. 30 (2000) p.579-583. doi:10.1016/S0008-8846(00)00210-6.

56.ELSHARIEF, A., COHEN, M.D., OLEK, J., Influence of aggregate size, water cement ratio and age on the microstructure of the interfacial transition zone, Cem. Concr. Res. 33 (2003) p.1837-1849. doi:10.1016/S0008-8846(03)00205-9.

57.BELAID, F., ARLIGUIE, G., FRANCOIS, R., Porous structure of the ITZ around galvanized and ordinary steel reinforcement, Cem. Concr. Res. 31 (2001) p.1561-1566. doi:https://doi.org/10.1016/ S0008-8846(01)00597-X.

$\overline{\text { Manuscript received: } 14.01 .2020}$ 